\title{
Correction to: Lean approach to improving performance and efficiency in a nuclear medicine department
}

\author{
Luca Burroni ${ }^{1}(0)$. Caterina Bianciardi ${ }^{2}$. Cinzia Romagnolo ${ }^{1}$. Chiara Cottignoli ${ }^{1}$ Andrea Palucci ${ }^{1}$. \\ Fabio Massimo Fringuelli ${ }^{1}$. Giuseppina Biscontini ${ }^{1}$. Jacopo Guercini ${ }^{3}$
}

Published online: 10 May 2021

(C) Italian Association of Nuclear Medicine and Molecular Imaging 2021

\section{Correction to: \\ Clinical and Translational Imaging (2021) 9:129-139 \\ https://doi.org/10.1007/s40336-021-00418-z}

In the original publication of the article, the given names and the family names of all authors were interchanged.

Luca Burroni ${ }^{1}$, Caterina Bianciardi ${ }^{2}$, Cinzia Romagnolo ${ }^{1}$, Chiara Cottignoli ${ }^{1}$, Andrea Palucci ${ }^{1}$, Fabio Massimo Fringuelli ${ }^{1}$, Giuseppina Biscontini ${ }^{1}$, Jacopo Guercini ${ }^{3}$

The correct authors' names are given above.

Publisher's Note Springer Nature remains neutral with regard to jurisdictional claims in published maps and institutional affiliations.

The original article can be found online at https://doi.org/10.1007/ s40336-021-00418-z.

Luca Burroni

luca.burroni@ospedaliriuniti.marche.it

1 Nuclear Medicine Unit, Ospedali Riuniti di Ancona Hospital, Via Conca 71, Ancona, Italy

2 Health Gestational Department, Alessandria Hospital, Alessandria, Italy

3 Heathcare Hospital Department, University Hospital, Pisa, Italy 